\section{Physiological Responses of Apple Rootstock M.9 to Infection by Fusarium solani}

\author{
Li Xiang, Lei Zhao, Mei Wang, Junxia Huang, Xuesen Chen, \\ Chengmiao Yin, and Zhiquan Mao \\ State Key Laboratory of Crop Biology/College of Horticultural Science and \\ Engineering, Shandong Agricultural University, Tai'an, 271018, Shandong, \\ China
}

Additional index words. apple replant disease, biotic stress response, reactive oxygen species, antioxidant enzyme activity, PR proteins

\begin{abstract}
Apple replant disease (ARD) causes enormous economic loss and threatens the survival of apple industry worldwide. Fusarium solani is one of the pathogens that has been proven to cause ARD. Samples were collected at different time periods to investigate the mechanism of defense responses of apple to $F$. solani infection by monitoring the biomass, reactive oxygen species (ROS), and antioxidant enzyme activities of the apple rootstock 'M.9T337'. In addition, the abundance of transcription of four pathogenesis-related (PR) proteins involved in antifungal defense was monitored. The results showed that the apple root system was normal and had small brown areas. However, there is a rapid burst of ROS during the early infection stage, and the activities of antioxidant enzymes and transcription of PRs increased during this period. With the extension in infection time, the infected root tissues displayed dark brown necrosis, and the activities of antioxidant enzymes and abundance of transcription of PRs decreased gradually after reaching their peak. Eventually, the plant biomass decreased, and the plant died. In conclusion, the levels of ROS and activities of antioxidant enzymes played an active role during the early stage of resistance of 'M.9T337' apples to infection by $F$. solani. Infection by $F$. solani can destroy the ROS scavenging system, causing oxidative damage and inhibiting the growth of apple rootstocks.
\end{abstract}

Apple replant disease (ARD) is a common disease in the world that occurs when orchards are replanted on sites that were previously planted with the same or similar tree species (Wang et al., 2019). The specific symptoms of ARD are growth retardation and the damage caused by diseases and insect pests, which leads to the shortening of lifespan of replanted fruit trees and dramatically hinders the sustainable development of apple industry (Laurent et al., 2008; Mazzola and Manici, 2012). Many researchers in China and worldwide have studied the causes of ARD for many years, and the factors that cause apple replant disease are highly

Received for publication 21 Apr. 2021. Accepted for publication 16 June 2021.

Published online 4 August 2021.

This research was supported by the National Natural Science Foundation of China (32072510), the earmarked fund for National Modern Agro-industry Technology Research System of China (CARS-27), Qingchuang Science and Technology Support Project of Shandong Colleges and Universities (2019KJF 020), the Natural Science Foundation Shandong Province (ZR2020MC131), the Fruit Innovation Team in Shandong Province, China (SDAIT-06-07), and Taishan Scholars (NO.ts20190923).

L.X. and L.Z. contributed equally to this work.

C.Y. and Z.M. are the corresponding authors.

E-mail: yinchengmiao@163.com or mzhiquan@ sdau.edu.cn.

This is an open access article distributed under the CC BY-NC-ND license (https://creativecommons. org/licenses/by-nc-nd/4.0/). complex (Spath et al., 2015; Tilston et al., 2018; Yin et al., 2018). Because disinfection of the soil can effectively prevent or mitigate this disease, the main factors that cause apple replant disease appear to be soilborne pathogens, combined with abiotic factors, such as autotoxic substances and soil structure and nutrition (Henfrey et al., 2015; Yim et al., 2013). Most research has demonstrated that fungal and oomycete genera are the main reasons for apple replant disease, i.e., the fungal genera Fusarium, Rhizoctonia, and Cylindrocarpon and the oomycete genera Phytophthora and Pythium (Manici et al., 2003; Tewoldemedhin et al., 2011a, 2011b, 2011c). Studies have shown that Fusarium is an important pathogen that causes ARD (Kelderer et al., 2012; Manici et al., 2013; Van Schoor et al., 2009). It is worth noting that there are a large number of Fusarium species in replanted apple soils in the Bohai Bay area, and apple rootstock are highly sensitive to these pathogens (Wang et al., 2018a).

The ROS scavenging system in plants regulates the balance of ROS and serves to maintain the normal redox state of cells. When pathogens infect plants, ROS are produced and rapidly burst (Dodds and Rathjen, 2010; Dou and Zhou, 2012). Common ROS are hydrogen peroxide $\left(\mathrm{H}_{2} \mathrm{O}_{2}\right)$ and superoxide radicals $\left(\mathrm{O}_{2} \cdot{ }^{-}\right)$among others (Mditshwa et al., 2017; Tian et al., 2015; Zhang et al., 2013). However, excessive ROS production can cause damage to the host cells (Berni et al., 2018; Wang et al., 2008). To maintain the best growth state, excessive amounts of ROS must be effectively removed to activate the plant antioxidant defense system (Mohsin and Adnan, 2017). The antioxidant enzyme defense system of plants primarily includes superoxide dismutase (SOD), peroxidase (POD), catalase (CAT), and ascorbate peroxidase (APX) (Li et al., 2016; Sharma and Dubey, 2007). SOD catalyzes the conversion of $\mathrm{O}_{2} \cdot{ }^{-}$into $\mathrm{H}_{2} \mathrm{O}_{2}$, and then CAT and POD degrade $\mathrm{H}_{2} \mathrm{O}_{2}$ into water and oxygen, thus, restoring the balance of metabolism of cellular ROS (Radwan et al., 2010; Zhang et al., 2016). APX catalyzes the reaction of ascorbic acid with $\mathrm{H}_{2} \mathrm{O}_{2}$ (Lv et al., 2017). Malondialdehyde (MDA) is a product of membrane lipid peroxidation produced during stress, and its content is often used as a marker to measure the degree of membrane lipid peroxidation (Li et al., 2004). The enhancement of activities of antioxidant enzymes can reduce the excessive amount of MDA produced by plants under stress, thus maintaining the stability of the cell membrane and enhancing plant tolerance to stress (Balal et al., 2012). Proline is a protective substance of plant cell membranes and enzymes that regulates the osmotic balance in cytoplasm (Ghoulam et al., 2002; Xing et al., 2017).

The enhanced expression and accumulation of PRs is the final result of induction of defense responses (Bonasera et al., 2006; Jones and Dangl, 2006). Most PRs have antifungal activity and can directly kill pathogens or inhibit the spread of diseases (Van Loon et al., 2006). Currently, MdPR2 (Mauch et al., 1988; Yin et al., 2013), MdPR4 (Bai et al., 2013), MdPR5 (Vigers et al., 1992), and $M d P R 8$ (Liu et al., 2013) are known to be present in apple.

Most studies currently use model plants, such as Arabidopsis thaliana and tomato (Solanum lycopersicum), to study the resistance of plants to infection by pathogens (Edgar et al., 2006; Mandal et al., 2009). $F$. solani is one of the pathogens that has been proven to cause ARD (Wang, 2018). Despite this, there is little information about the defense responses of apples to infection by $F$. solani. The aim of this study was to determine the mechanism by which apple rootstocks 'M.9T337' activate their defense responses during infection by $F$. solani. We monitored the dynamic changes in ROS content and antioxidant enzyme activities in apple root systems during infection with $F$. solani and examined a group of PRs that are involved in antifungal defense in the defense signaling pathway using quantitative realtime polymerase chain reaction (qRT-PCR).

\section{Materials and Methods}

Plant material and F. solani inoculation. The apple rootstock 'M.9T337' was used in this study, and plants were grown in a greenhouse in Shandong Agricultural University (Taian, Shandong, China). The plants were grown in loam soil. They were acclimatized for 4 weeks in a greenhouse, and the rootstock 
was grown in $16 \mathrm{~h}$ light $/ 8 \mathrm{~h}$ dark at 23 to $25^{\circ} \mathrm{C}$ and a relative humidity of $60 \%$ to $75 \%$.

In this study, the $F$. solani (MG836251.1) was originally isolated from apple roots around the Bohai Bay, China (Wang, 2018). $F$. solani was inoculated in potato dextrose agar (PDA; Hopebio, Qingdao, China) liquid media for $120 \mathrm{~h}$ and then filtered through eight layers of sterilized gauze. A spore suspension of $F$. solani was obtained by filtration, and its concentration was determined using a hemocytometer (ThermoFisher Scientific, Waltham, MA) under a microscope (Ni-U; Nikon, Tokyo, Japan). Sterile water was added to adjust its final concentration to $10^{5}$ cells $/ \mathrm{mL}$. The spore suspension $(50 \mathrm{~mL})$ of $F$. solani was separately inoculated into the nutrients provided to the rootstock. The control group receiving the same volume of sterile water. The inoculated rootstock were cultured in the greenhouse. Apple roots were sampled at 0,1 , 3,5 , and $7 \mathrm{~d}$ after infection, immediately frozen in liquid nitrogen, and stored at $-80^{\circ} \mathrm{C}$. The root samples of control treatment and $F$. solani infection were stored in water and observed within $2 \mathrm{~h}$ after sampling using a stereoscope (NSZ608T; Jiang Nan, China).

Determination of apple biomass and root morphology. On day 20 after infection, six plants with the same growth were randomly selected, and the fresh plants were harvested and their fresh weight (FW) determined. The roots were overlaid on transparent hard plastic sheets $(1.5 \mathrm{~cm})$ and then spread out in water. Root scanning patterns were obtained using a professional version of the WinRHIZO (2016 version; Ruifeng, Guangzhou, China) root analysis system to record the total root length, root area, root volume, and root tips. Subsequently, the plants were dried to a constant weight at $70^{\circ} \mathrm{C}$ in an oven (DHG, Jinghong, Shanghai, China) and weighed [dry weight (DW)].

Determination of $\mathrm{H}_{2} \mathrm{O}_{2}, \mathrm{O}_{2}^{-}, \mathrm{MDA}$, and proline. The concentration of $\mathrm{H}_{2} \mathrm{O}_{2}$ was determined using ultraviolet spectrophotometry (Patterson et al., 1984). A total of $0.5 \mathrm{~g}$ of frozen roots was homogenized with $2.5 \mathrm{~mL}$ of chilled acetone in a mortar and pestle and then centrifuged for $10 \mathrm{~min}$ at $10,000 \mathrm{rpm}$ at $4{ }^{\circ} \mathrm{C}$. The absorbance of a peroxide titanium complex was determined at $415 \mathrm{~nm}$. The absorbance values were calibrated based on the standard curve and expressed as $\mathrm{mmol} \cdot \mathrm{g}^{-1}$ FW. The rate of $\mathrm{O}_{2} .^{-}$was determined using the hydroxylamine reaction method and expressed as $\mathrm{mmol} \cdot \mathrm{g}^{-1} \mathrm{FW}$ (Bai et al., 2009). The content of MDA was determined using the thiobarbituric acid method (Bai et al., 2009). A total of $0.5 \mathrm{~g}$ of frozen roots was homogenized with $5 \mathrm{~mL} 10 \%$ trichloroacetic acid in a mortar and pestle and then centrifuged for $10 \mathrm{~min}$ at $4000 \mathrm{~g}_{\mathrm{n}}$ at $4{ }^{\circ} \mathrm{C}$. Twocomponent spectrophotometry was then used to directly calculate the concentration of MDA in plant samples. The content of proline was measured using the ninhydrin coloration method (Wang et al., 2015d). A standard curve for the amount of proline was used to determine the final calculations. A total of $0.5 \mathrm{~g}$ of frozen roots was cut and placed in a large test tube. A volume of $5 \mathrm{~mL}$ of $3 \%$ sulfosalicylic acid was added to the test tube, which was then covered with a glass ball and extracted in a boiling water bath for $10 \mathrm{~min}$. An ultraviolet spectrophotometer (ultraviolet2600; Shimadzu, Tokyo, Japan) was used to measure the absorbance at $520 \mathrm{~nm}$.

Determination of the enzymatic activities of apple roots. The activities of SOD, POD, CAT, and APX were determined as previously described (Wang et al., 2014b). A volume of $8 \mathrm{~mL} 0.05 \mathrm{mmol} \cdot \mathrm{L}^{-1}$ phosphate buffer ( $\mathrm{pH}$ 7.8) was added to $1 \mathrm{~g}$ of fresh roots in a mortar and pestle to which a small amount of quartz stone was added. The mixture was centrifuged for $20 \mathrm{~min}$ at $12,000 \mathrm{~g}_{\mathrm{n}}$ at $4{ }^{\circ} \mathrm{C}$. The supernatant was used to determine the enzyme activity. The activity of SOD was determined using nitroblue tetrazolium (NBT) photoreduction. One unit (U) of SOD activity was defined as the amount of enzyme that caused $50 \%$ of the maximum inhibition of the reduction of NBT, and the activity of SOD is expressed as $\mathrm{U} \cdot \mathrm{g}^{-1} \mathrm{FW}$. The activity of POD was determined by measuring the oxidation of guaiacol. One unit of POD was defined as the amount of enzyme that caused an increase of 0.1 in the absorbance at $470 \mathrm{~nm} / \mathrm{min}$, and the activity of POD is expressed as $\mathrm{U} \cdot \mathrm{g}^{-1} \cdot \mathrm{min}^{-1} \mathrm{FW}$. The activities of CAT and APX were determined using ultraviolet spectrophotometry. One unit of CAT and APX was defined as the amount of enzyme that caused a change of 0.1 in the absorbance at 270 and $290 \mathrm{~nm} / \mathrm{min}$, respectively. The activities of CAT and APX are expressed as $\mathrm{U} \cdot \mathrm{g}^{-1} \cdot \mathrm{min}^{-1} \mathrm{FW}$. The test was conducted in triplicate.

Analysis of the expression of genes using $q R T-P C R$. The total RNA was extracted using a Plant RNA Purification Kit (Vazyme, Nanjing, China), and its concentration and quality were measured using a NanoDrop 2000 spectrophotometer (ThermoFisher Scientific). First-strand cDNA was synthesized from $1 \mu \mathrm{g}$ of total RNA using a RevertAid First Strand cDNA Synthesis Kit (TransGen Biotech, Beijing, China), and the qRT-PCR reactions were performed using SYBR Green PCR Master Mix (TransGen Biotech). The sequences of primers used are shown in Table 1. The
cDNA was amplified under the following conditions: $95^{\circ} \mathrm{C}$ for $30 \mathrm{~s}$; then 35 cycles of $95^{\circ} \mathrm{C}$ for $5 \mathrm{~s}, 58^{\circ} \mathrm{C}$ for $30 \mathrm{~s}$, and $72^{\circ} \mathrm{C}$ for $20 \mathrm{~s}$. The relative quantification of specific mRNA concentrations was conducted using the cycle threshold $(\mathrm{Ct}) 2^{-\Delta \Delta \mathrm{Ct}}$ method (SoftwareIQ5 2.0, Bio-Rad, Hercules, CA) with MdAct as an internal control (Wang et al., 2015b; Zhang and Shi, 2015). The RT-qPCR experiments were conducted in triplicate.

Statistical analysis. The data were expressed as the means and standard errors (SE) of three biological replicates. Statistical calculations were performed using SPSS v. 19.0 (IBM, Inc., Armonk, NY) and Microsoft Excel 2010 (Redmond, WA). The data were analyzed using SPSS v. 19.0 for Windows. The graphs were drawn with GraphPad Prism 8 (San Diego, CA).

\section{Results}

F. solani inhibited the growth of 'M.9T337'. We selected plants with consistent growth for infection (Fig. 1A). After $30 \mathrm{~d}$, a large number of plants were diseased owing to infection by $F$. solani with a rate of incidence rate of $79.17 \%$ (Fig. 1C), and some plants died (Fig. 1B). The mortality rate was $33.3 \%$ (Fig. 1D). After $20 \mathrm{~d}$ of infection, the FW of the infected plants averaged $2.61 \mathrm{~g}$ compared with $5.03 \mathrm{~g}$ for the controls (Fig. 2A). Following infection, FW and DW decreased dramatically by $48.11 \%$ and $54.41 \%$, respectively (Fig. 2B). We found that the apple root growth was significantly inhibited $20 \mathrm{~d}$ after inoculation using the root analysis system. Compared with the control, the root length, root area, root volume, and number of root tips were reduced by $48.78 \%$, $52.89 \%, 55.64 \%$, and $61.48 \%$, respectively (Fig. 3). We observed the symptoms of the apple rootstock 'M.9T337' root tissue after infection by $F$. solani (Fig. 4A). At 1 d postinoculation (dpi), no obvious lesions were observed in the apple root tissue. At 3 dpi, the infected root tissues were normal in color, but a few brown areas appeared. At 5 dpi, the entire apple root tissue inoculated with $F$. solani had browned slightly and was accompanied by tissue depression. At $7 \mathrm{dpi}$, the root tissues infected with $F$. solani exhibited extensive browning, a dense distribution of brown areas, and necrosis of the root tips (Fig. 4B).

Effects of $\mathrm{F}$. solani on the contents of $\mathrm{H}_{2} \mathrm{O}_{2}, \mathrm{O}_{2}{ }^{-}, \mathrm{MDA}$, and proline in 'M.9T337' apple roots after infection. The inoculation of $F$. solani sharply increased the level of $\mathrm{H}_{2} \mathrm{O}_{2}$, which reached its highest level at 1 dpi (3.22 $\mu \mathrm{mol} \cdot \mathrm{g}^{-1} \mathrm{FW}$ ) and then began to gradually decline (Fig. 5A). The level of $\mathrm{O}_{2} .^{-}$also increased sharply, reaching its highest peak at 3

Table 1. Primers used in the quantitative real-time polymerase chain reaction analysis of gene expression.

\begin{tabular}{|c|c|c|c|}
\hline Gene ID & Gene name & Forward primer & Reverse primer \\
\hline$\overline{\text { MDP0000570395 }}$ & MdPR2 & 5'-AACACACCAAATTCAAATGGAC-3' & 5'-GAAGTCAAGGGAAGGAAAGG-3' \\
\hline MDP0000782085 & MdPR4 & 5'-ATACCACCTCTACAATCCACA-3' & 5'-GTCCAAGTCCAATCCTCC-3' \\
\hline MDP0000552328 & MdPR5 & 5'-CTCACCTTGGCCATCCTCTT-3' & 5'-TTGGATGCTAGTTCGAAGC-3' \\
\hline MDP0000222724 & MdPR8 & 5'-CAAAACGGCAACGAAGGAAC-3' & 5'-AAGTACCACTAGCGGGGTT-3' \\
\hline MDP0000417095 & MdActin & 5'-TGACCGAATGAGCAAGGAAATTACT-3' & 5'-TACTCAGCTTTGGCAATCCACATC-3' \\
\hline
\end{tabular}




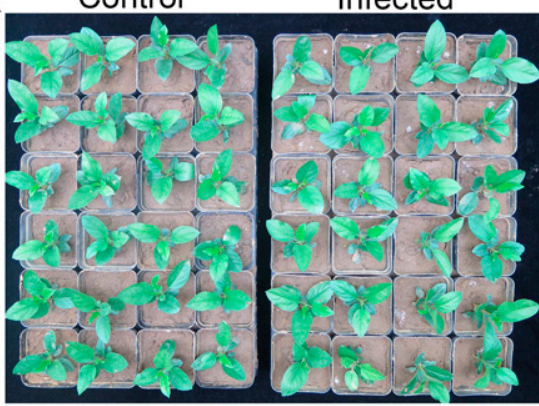

C

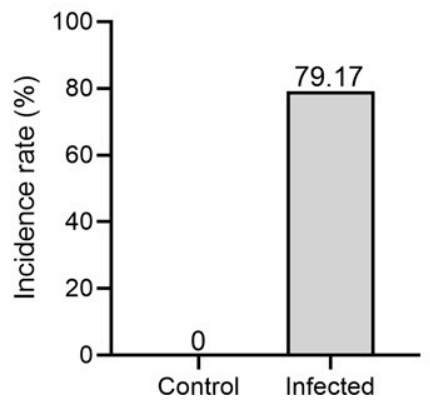

B

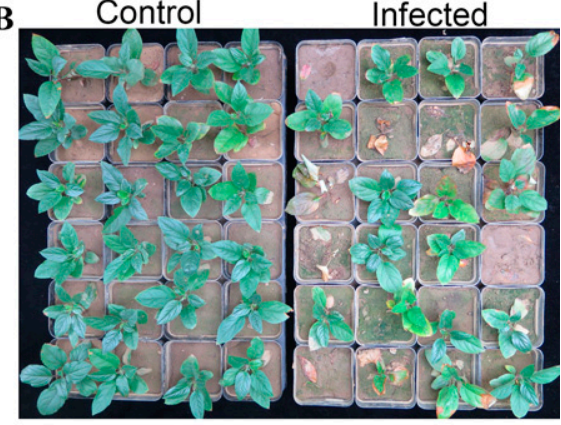

D

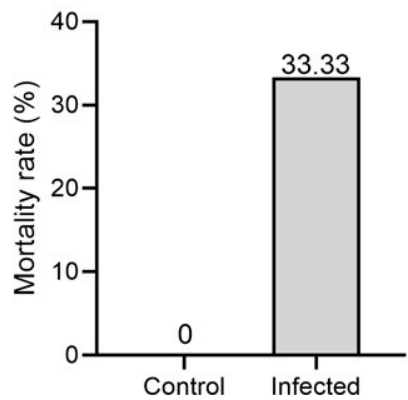

Fig. 1. Response of 'M.9T337' plants to infection with Fusarium solani and the control. (A) Plant at the time of planting. (B) Plant after $30 \mathrm{~d}$ of infection. (C) Incidence rate. (D) Mortality rate.

dpi $\left(1.04 \mathrm{nmol} \cdot \mathrm{g}^{-1} \mathrm{FW}\right)$ and then began to decline (Fig. 5B). Compared with the control, infection with $F$. solani caused a rapid burst and accumulation of ROS in apple roots. Inoculation with $F$. solani increased the permeability of apple root cell membranes, which showed that the MDA content increased sharply at 1 dpi, peaked at $5 \mathrm{dpi}\left(7.05 \mathrm{mmol} \cdot \mathrm{g}^{-1} \mathrm{FW}\right)$, and then began to decline (Fig. 5C). The inoculation of $F$. solani also sharply increased the level of proline at $1 \mathrm{dpi}$, which then increased slowly, reaching its highest level at $5 \mathrm{dpi}\left(0.84 \mathrm{mg} \cdot \mathrm{g}^{-1}\right.$ FW) and decreased slightly at 7 dpi (Fig. 5D).

Effect of $\mathrm{F}$. solani infection on antioxidant enzyme activities in 'M.9T337' apple roots. The activities of four enzymes in the control root tissues did not change significantly in contrast to the roots infected by $F$. solani. Compared with the control, inoculation with the pathogen caused a significant increase in

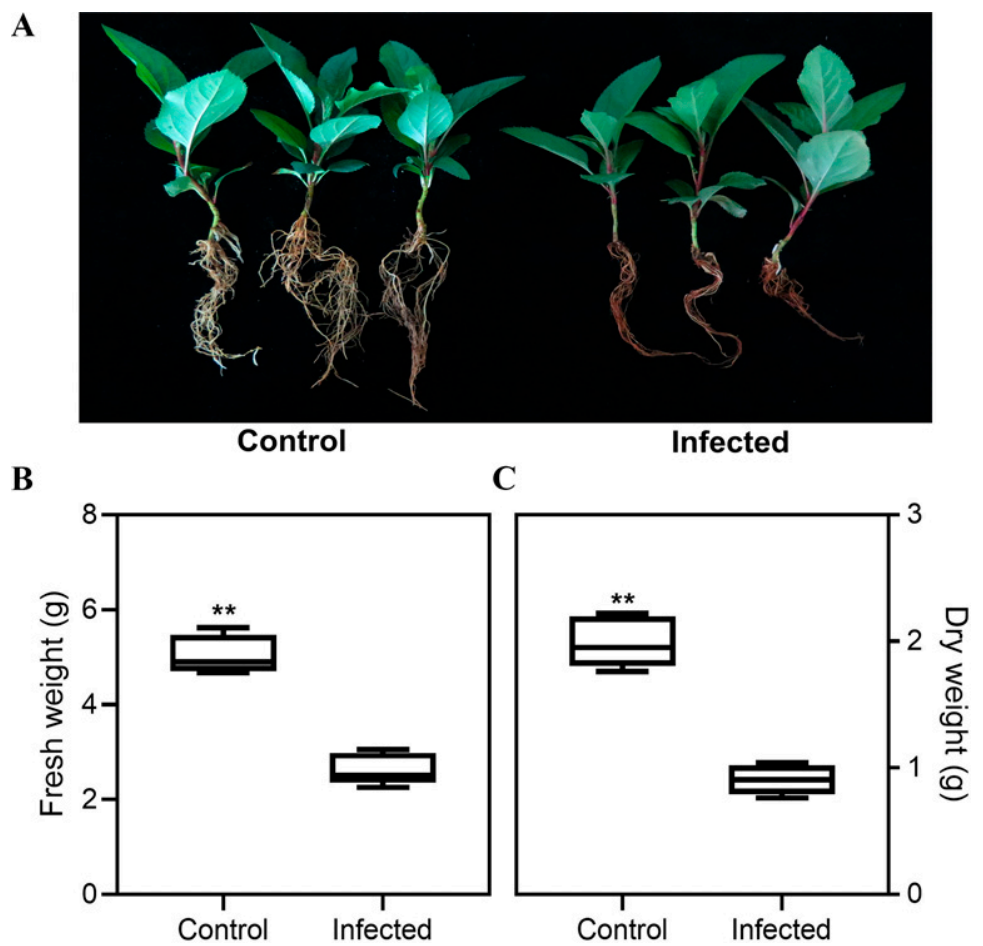

Fig. 2. The biomass of 'M.9T337' after $20 \mathrm{~d}$ of infection with Fusarium solani. (A) Plant after $20 \mathrm{~d}$ of infection. (B) Fresh weight (FW). (C) Dry weight (DW). Data show the means \pm SD of six independent samples. ${ }^{* *}$ Extremely significant difference at the 0.01 level.

SOD activity at $1 \mathrm{dpi}$, which reached its highest levels at $3 \mathrm{dpi}\left(170.82 \mathrm{U} \cdot \mathrm{g}^{-1} \mathrm{FW}\right)$, and then began to decline rapidly, resulting in a value lower than that of the control at $7 \mathrm{dpi}$ (Fig. 6A). The activities of POD and CAT showed the same trend. After inoculation, the activities of POD and CAT increased significantly, reaching their peak at 3 dpi $(81.39$ $\mathrm{U} \cdot \mathrm{g}^{-1} \cdot \mathrm{min}^{-1} \mathrm{FW}$ and $39.79 \mathrm{U} \cdot \mathrm{g}^{-1} \cdot \mathrm{min}^{-1}$ $\mathrm{FW}$, respectively) and then decreased rapidly, resulting in a value lower than that of the control (Fig. 6B and C) at 7 dpi. At 3 dpi, it was $72.14 \%$ and $74.48 \%$ higher than that of the control, respectively. The activity of APX reached its peak at $3 \mathrm{dpi}\left(124.83 \mathrm{U} \cdot \mathrm{g}^{-1} \cdot \mathrm{min}^{-1}\right.$ $\mathrm{FW}$ ) and then reached the same level as the control at 7 dpi (Fig. 6D).

Effect of $\mathrm{F}$. solani infection on the abundance of PR gene transcripts in 'M.9T337' apple roots. Compared with the control group, $F$. solani induced the expression of $M d P R 2, M d P R 4, M d P R 5$, and MdPR8. However, there were different transcriptional abundances of the PRs. At 3 dpi, the abundance of MdPR2, MdPR4, MdPR5, and $M d P R 8$ transcripts increased by $11.31,33.31$, 101.97, and 26.30 times, respectively. The abundance of four PR transcript subsequently decreased over time (Fig. 7).

\section{Discussion}

ARD causes enormous economic loss and threatens the survival of the apple industry worldwide; it primarily manifests as an imbalance in the microbial community structure and an increase in deleterious fungi as shown in early research (Yin et al., 2017a). Studies have shown that the types of detrimental fungi vary in the replant soil of orchards in different areas (Manici et al., 2013). We used tissue culture without rootstock propagation stage pathogens. We collected samples at different time periods to investigate the defense response mechanism of the response of apple to $F$. solani infection by monitoring the biomass, antioxidant enzyme activity, and transcriptional abundance of PRs in the apple rootstock 'M.9T337'.

After the apple was infected by pathogens, the initial defense response was closely related to the accumulation of ROS (Cao et al., 2017). ROS is primarily produced in the plasma membrane of plants by NADPH oxidase and in peroxisomes and mitochondria as a byproduct catalyzed by a variety of oxidases (Berni et al., 2018). The rapid production and outbreak of ROS is an early reaction to the perception of a plant that it has been infected by a pathogen (Dodds and Rathjen, 2010; Dou and Zhou, 2012). We found that $\mathrm{H}_{2} \mathrm{O}_{2}$ and $\mathrm{O}_{2}{ }^{-}$increased significantly during the early stage of infection (Fig. 5). ROS is involved in the mechanism of plant disease resistance; it is toxic to pathogens and directly sterilizes them (Shetty et al., 2008). However, excessive ROS reacts with proteins, lipids, and nucleic acids in host cells, causing the peroxidation of cell membranes and inactivation of enzymes, resulting in cell metabolic disorder and host cell death (Wang et al., 

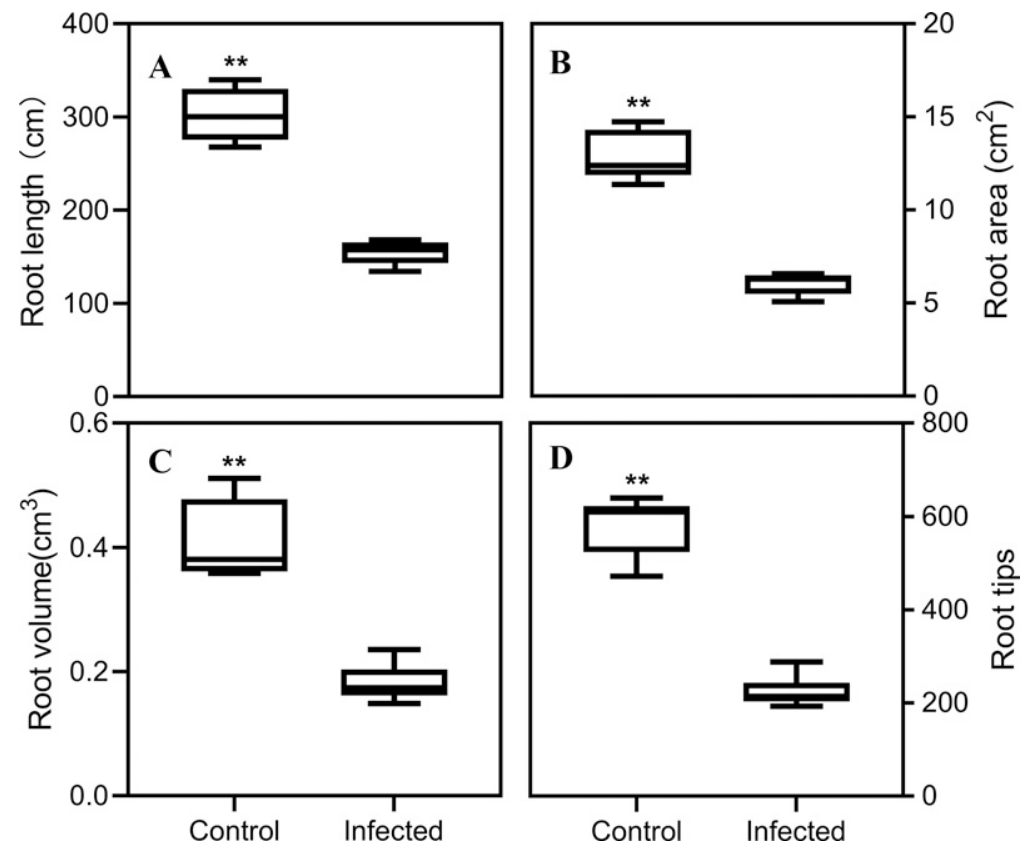

Fig. 3. Effects of Fusarium solani on the 'M.9T337' root morphology at 20 dpi. (A) Total root length of apple. (B) Total root area of apple. (C) Total root volume of apple. (D) Total root tips of apple. Data show the means \pm SD of six independent samples. ${ }^{* *}$ Extremely significant difference at the 0.01 level.

2008, 2016). The complete ROS clearance system regulates the balance of the host ROS, and thus maintains the normal redox state of the cells and reduces damage to host cells

A

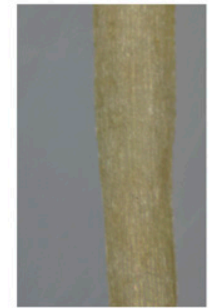

Od

B
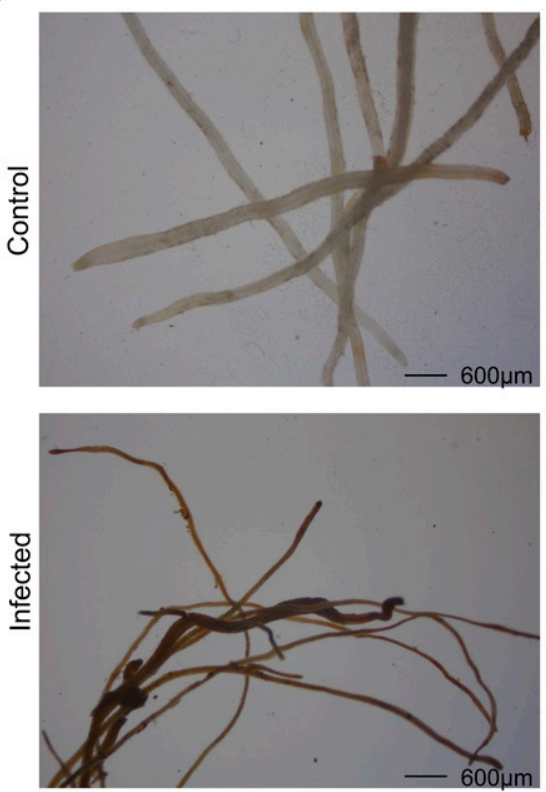

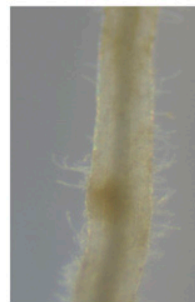

$1 d$
(Mohsin and Adnan, 2017). By increasing the activities of defense enzymes, such as SOD, POD, and CAT, the level of ROS can be regulated to reduce the toxicity of its excessive

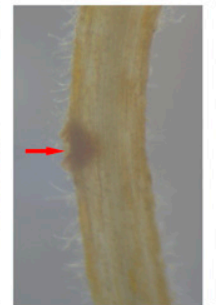

$5 d$
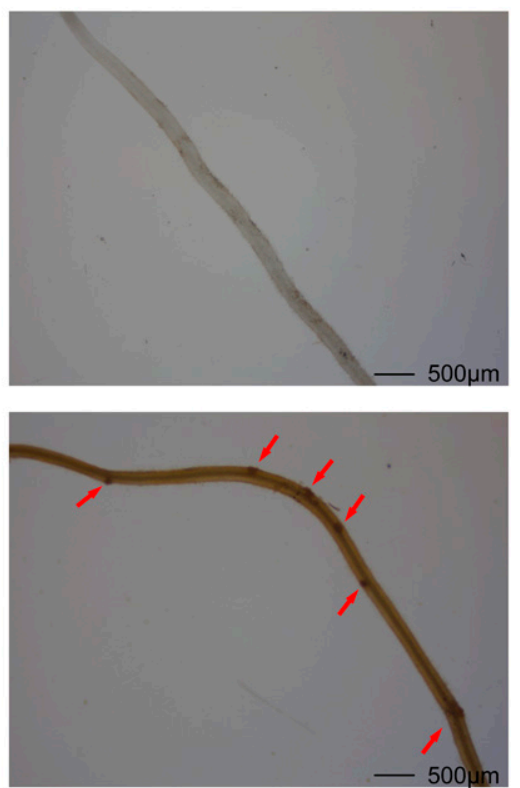

Fig. 4. The micro morphology of 'M.9T337' of infection with Fusarium solani. The root samples of control treatment and $F$. solani infection were observed after sampling under stereoscope. (A) 0 to $7 \mathrm{~d}$. (B) At 7 days post-inoculation (dpi). Arrows indicate the regions with tissue necrosis. accumulation on apple, thereby enhancing the resistance of apple to Botrytis cinerea (Meng et al., 2019). We found that the activities of antioxidant enzymes increased to varying degrees after $F$. solani infection (Fig. 6). The excessive production of ROS was removed by defense-related enzymes in the apple roots, such as SOD, POD, CAT, and APX (Lv et al., 2017; Radwan et al., 2010; Wang et al., 2015c). This showed that the antioxidant system plays an active role in the early stage of resistance of apple rootstock M.9T337 to infection by $F$. solani. We found that the four types of enzyme activities had decreased to varying degrees at $7 \mathrm{dpi}$ and were even lower than the control, indicating that the enzyme activity produced by apple itself was not enough to reduce its excess of ROS. Thus, the ROS causes damage to the cells and inactivates enzymes.

MDA is the final decomposition product of membrane lipid peroxidation, and its content can reflect the degree of plant injury (Adams et al., 2008; Zhang and Shi, 2015). Compared with the susceptible variety 'Fuji', the resistant variety Malus hupehensis is strongly resistant to the peroxidation of its lipid membranes, thus protecting the integrity of cell membrane structure and improving its ability to resist Valsa mali (Wang et al., 2014a). The content of MDA increased significantly in the early stage $(0-5 \mathrm{~d})$ of $F$. solani infection and then began to decrease at 7 dpi (Fig. 5C). When the activity of antioxidant enzymes decreased, the content of MDA was still increasing. Although it has been reported that the increase in antioxidant enzyme activity can reduce the excessive production of MDA by plants (Balal et al., 2012), the accumulation of excessive MDA can lead to leakage of the cytoplasm and cell death in severe cases (Hui et al., 2013; Kuk et al., 2003). Therefore, we hypothesize that the damage to the cell membrane system may be related to the peroxidation of membrane lipids caused by free radicals and ROS. Soilborne pathogens infect the xylem of plant roots, which hinders the transportation of water (Yan et al., 2018), resulting in severe water deficit stress and the wilting of apple rootstock (Wang et al., 2015a). Malus hupehensis accumulates proline to improve resistance under replanting conditions (Wang et al., 2014a). Plants can accumulate proline, an important osmotic regulator, to avoid the excessive loss of water caused by the infection of soilborne pathogens and maintain the stability of cell membranes (Delauney and Verma, 1993).

PRs are types of proteins secreted by plant cells that are not easily hydrolyzed, have a low molecular weight, and specifically accumulate in response to external biotic stress (Wang et al., 2018b). Most PRs have direct antifungal effects, and transgenic plants that express PRs can improve their resistance to some pathogenic microorganisms (Alexander et al., 1993; Sels et al., 2008). Among them, there has been a substantial amount of research on enzymes (PR2, PR4, and PR8) that can degrade the cell wall of pathogens (Odintsova et al., 2010; Van Loon et al., 

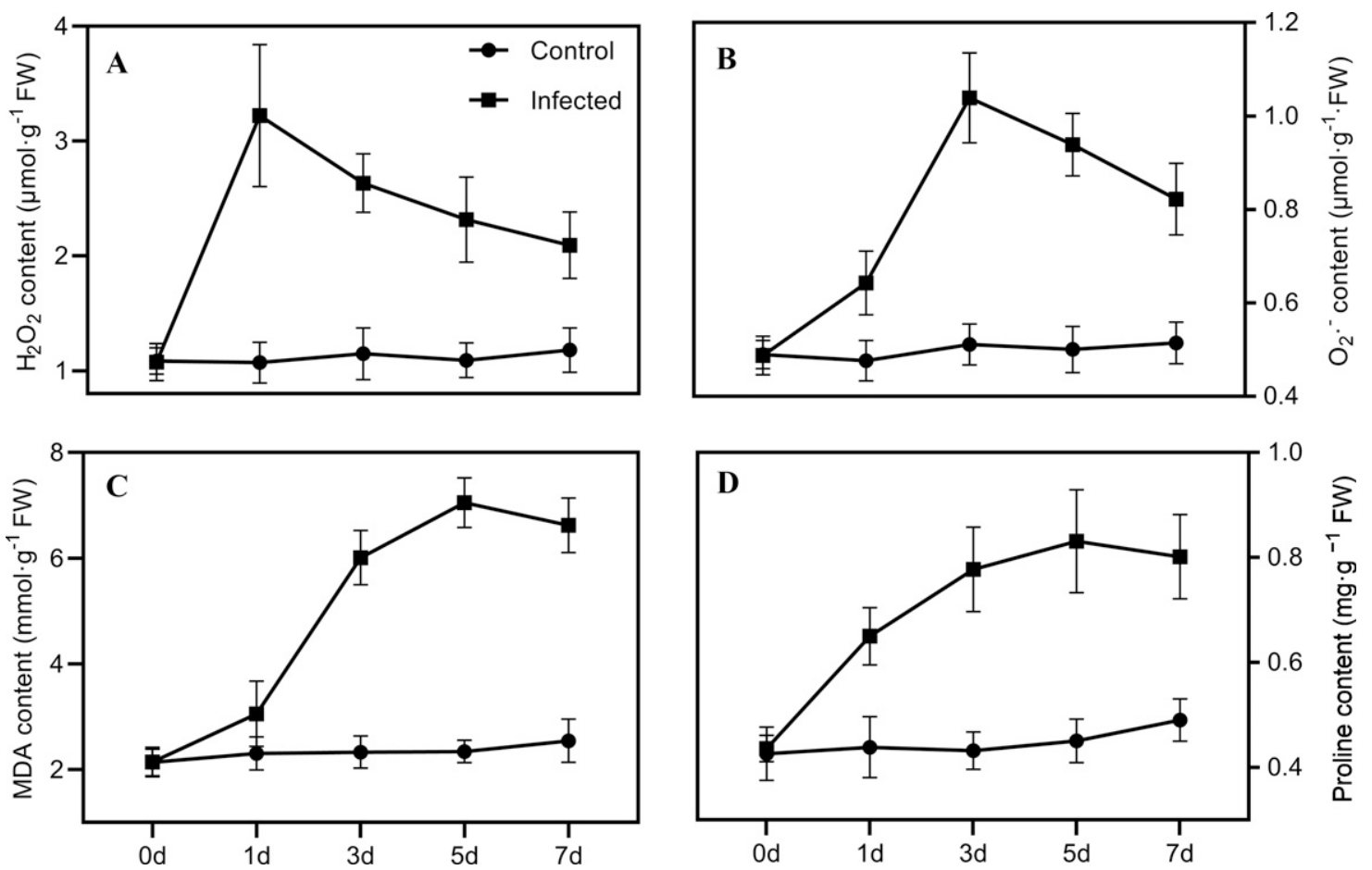

Fig. 5. Effect of Fusarium solani on the contents of $\mathrm{H}_{2} \mathrm{O}_{2}, \mathrm{O}_{2}{ }^{-}$, MDA and proline in 'M.9T337' apple roots after infection. After the various intervals, root tissues were collected to determine the contents of (A) $\mathrm{H}_{2} \mathrm{O}_{2}$, (B) $\mathrm{O}_{2}{ }^{-}$, (C) malondialdehye (MDA), and (D) proline.

2006). $\beta$-1,3-glucanases and acid endoglucanase are the key PR proteins of the response of apples infected by Botryosphaeria berengeriana (Sun et al., 2018). The level of expression of PR proteins was significantly upregulated after the infection of apple branches by $B$. berengeriana (Zhang et al., 2015). The levels of expression of $M d P R 2$, $M d P R 4, M d P R 5$, and MdPR8 increased rapidly after inoculation with $F$. solani compared with control (Fig. 7). This observation is consistent with that of Zhang et al. (2016). Pathogens can induce the expression of MdPR5 (Bonasera et al., 2006; Gau et al., 2004). PR5 is a thaumatin-like protein that can degrade fungal cell membranes and has antifungal activity (Vigers et al., 1992). This suggests that the expression of PR genes may be involved in the defense response of 'M.9T337' to infection with $F$. solani.
As the outermost layer of the root, the epidermis is involved in protecting the root and cortex. The cortex is the main component of root, which primarily acts as the storage tissue of photosynthetic products and actively absorbs water and minerals (Beeckman, 2010; Gregory, 2006). The accumulation of large amounts of ROS in apple rootstock roots could lead to the metabolic dysfunction of root cells during the process of infection
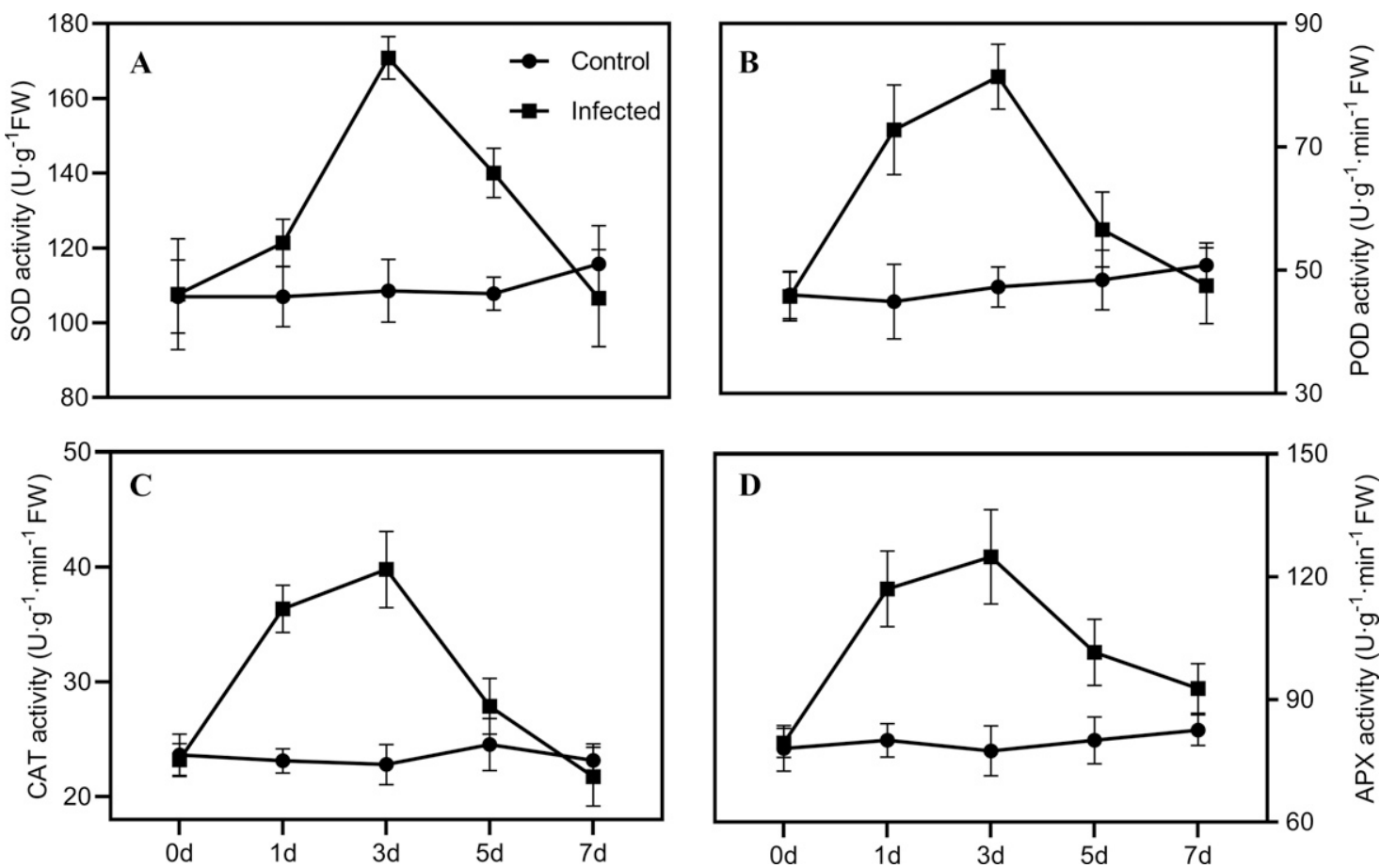

Fig. 6. Effect of Fusarium solani on antioxidant enzyme activities in 'M.9T337' apple root after infection. After the various intervals, root tissues were collected to determine the activities of (A) superoxide dismutase (SOD), (B) peroxidase (POD), (C) catalase (CAT), and (D) ascorbate peroxidase (APX). 


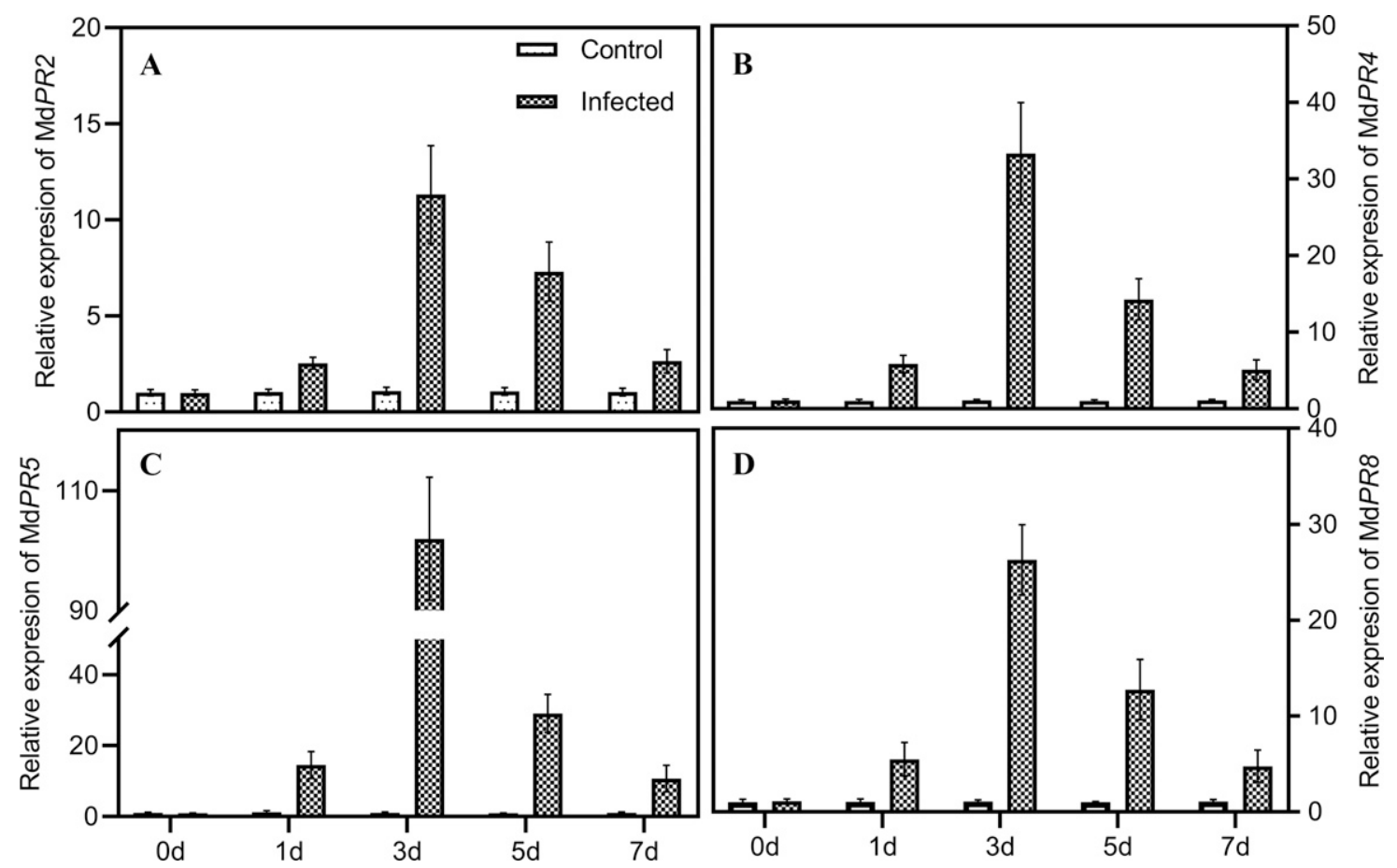

Fig. 7. Effect of Fusarium solani on the transcript abundance of (A) PR2, (B) PR4, (C), PR5, and (D) and PR8 genes in 'M.9T337' apple roots after infection. Total RNA was extracted from the leaf tissues frozen at different time points, converted to cDNA, and subjected to quantitative real-time polymerase chain reaction. The data represent the mean of two separate experiments with three biological replicates.

by F. solani (Berni et al., 2018), and the plant defense system would be destroyed, which leads to the lysis of epidermal cells and the disintegration of cortical cells, root tip necrosis and an almost complete loss of functional root hairs (Caruso et al., 1989; Yim et al., 2013). With extension in the time of infection, the growth of plant was significantly inhibited by infection with $F$. solani, and the $\mathrm{FW}$ and DW decreased significantly (Fig. 2). By analyzing the root morphology, we found that the apple root length, root area, root volume, and root tip numbers decreased significantly (Fig. 3). After $30 \mathrm{~d}$ of $F$. solani infection, a large number of apple rootstock died (Fig. 1).

\section{Conclusions}

The study showed that a series of defense responses were induced against $F$. solani during infections in 'M.9T337' apple roots, including an enhancement of defense-related enzyme activities and the upregulation of expression of PR genes. F. solani inhibits apple growth by destroying the defense system of apple roots. These findings highlight the importance of unraveling the defense mechanism of plants against soilborne pathogens, but more research to understand the interactions between the apple root system and pathogens involved in apple replant disease is merited.

\section{Literature Cited}

Adams, A., N. De Kimpe, and M.A.J.S. van Boekel. 2008. Modification of casein by the lipid oxidation product malondialdehyde. J. Agr. Food Chem. 56:1713-1719, doi: 10.1021/jf0 $72385 b$.
Alexander, M., R.M. Goodman, M. Gut-Rella, C. Glascock, K. Weymann, L. Friedrich, D. Maddox, P. Ahl-Goy, T. Luntz, and E. Ward. 1993. Increased tolerance to two oomycete pathogens in transgenic tobacco expressing pathogenesisrelated protein 1a. Proc. Natl. Acad. Sci. USA 90:7327-7331, doi: 10.1073/pnas.90.15.7327.

Bai, R., F. Ma, D. Liang, and X. Zhao. 2009. Phthalic acid induces oxidative stress and alters the activity of some antioxidant enzymes in roots of Malus prunifolia. J. Chem. Ecol. 35:488-494, doi: 10.1007/s10886-009-9615-7.

Bai, S.H., C.H. Dong, B.H. Li, and H.Y. Dai. 2013. A PR-4 gene identified from Malus domestica is involved in the defense responses against Botryosphaeria dothidea. Plant Physiol. Biochem. 62:23-32, doi: 10.1016/j.plaphy.2012. 10.016.

Balal, R.M., M.M. Khan, M.A. Shahid, N.S. Mattson, and Z. Iqbal. 2012. Comparative studies on the physiobiochemical, enzymatic, and ionic modifications in salt-tolerant and salt-sensitive citrus rootstocks under $\mathrm{NaCl}$ stress. J. Amer. Soc. Hort. Sci. 137:86-95, doi: 10.1016/j.post harvbio.2011.12.001.

Beeckman, T. 2010. Root development. Annual Plant Reviews 37. Blackwell Publishing Ltd., Hoboken, NJ.

Berni, R., M. Luyckx, X. Xu, S. Legay, K. Sergeant, J.F. Hausman, S. Lutts, G. Cai, and G. Guerriero. 2018. Reactive oxygen species and heavy metal stress in plants: Impact on the cell wall and secondary metabolism. Environ. Exp. Bot. 161:98-106, doi: 10.1016/j.envexpbot. 2018.10.017.

Bonasera, J.M., J.F. Kim, and S.V. Beer. 2006. PR genes of apple: Identification and expression in response to elicitors and inoculation with Erwinia amylovora. BMC Plant Biol. 6:23, doi: 10.1186/1471-2229-6-23.

Cao, J.J., Z.C. Yu, Y. Zhang, B.H. Li, W.X. Liang, and C.X. Wang. 2017. Control efficiency of exogenous melatonin against postharvest apple grey mold and its influence on the activity of defensive enzymes. Plant Physiol. J. 53:17531760, doi: 10.13592/j.cnki.ppj.2017.0197.

Caruso, F.L., B.F. Neubauer, and M.D. Begin. 1989. A histological study of apple roots affected by replant disease. Can. J. Bot. 67:742-749, doi: 10.1139/b89-100.

Delauney, A.J. and D.P.S. Verma. 1993. Proline biosynthesis and osmoregulation in plants. Plant J. 4:215-223, doi: 10.1046/j.1365-313X 1993.04020215.x.

Dodds, P.N. and J.P. Rathjen. 2010. Plant immunity: Towards an integrated view of plant-pathogen interactions. Nat. Rev. Genet. 11:539-548, doi: $10.1038 / \mathrm{nrg} 2812$.

Dou, D.L. and J.M. Zhou. 2012. Phytopathogen effectors subverting host immunity: Different foes, similar battleground. Cell Host Microbe 12:484-495, doi: 10.1016/j.chom.2012.09.003.

Edgar, C.I., K.C. Mcgrath, B. Dombrecht, J.M. Manners, and K. Kazan. 2006. Salicylic acid mediates resistance to the vascular wilt pathogen Fusarium oxysporum in the model host Arabidopsis thaliana. Australas. Plant Pathol. 35:581-591, doi: 10.1071/AP06060

Gau, A.E., M. Koutb, M. Piotrowski, and K. Kloppstech. 2004. Accumulation of pathogenesis-related proteins in the apoplast of a susceptible cultivar of apple (Malus domestica $\mathrm{cv}$. Elstar) after infection by Venturia inaequalis and constitutive expression of PR genes in the resistant cultivar Remo. Eur. J. Plant Pathol. 110:703-711, doi: 10.1023/B:EJPP.0000041552.98673.e3.

Ghoulam, C., A. Foursy, and K. Fares. 2002. Effects of salt stress on growth, inorganic ions and proline accumulation in relation to osmotic adjustment in five sugar beet cultivars. Environ. Exp. Bot. 47:39-50, doi: 10.1016/S0098-8472(01) 00109-5.

Gregory, P.J. 2006. Plant roots: Growth, activity and interaction with soils. Blackwell, Oxford, UK.

Henfrey, J.L., G. Baab, and M. Schmitz. 2015. Physiological stress responses in apple under replant 
conditions. Scientia Hort. 194:111-117, doi: 10.1016/j.scienta.2015.07.034.

Hui, Z.M., Z.Z. Wang, Y. Hu, M.M. Deng, and Z.W Zhang. 2013. Effects of 24-epibrassinolide on the antioxidant system and osmotic adjustment substance in grape seedlings $(V$. vinifera $\mathrm{L}$.) under chilling stress. Sci. Agr. Sin. 46:1005-1013, doi: 10.3864/j.issn.0578-1752.2013.05.016.

Jones, J.D. and J.L. Dangl. 2006. The plant immune system. Nature 444:323-329, doi: 10.1038 /nature 05286 .

Kelderer, M., L.M. Manici, F. Caputo, and M. Thalheimer. 2012. Planting in the "inter-row" to overcome replant disease in apple orchards: A study on the effectiveness of the practice based on microbial indicators. Plant Soil 357:381-393, doi: 10.1007/s11104-012-1172-0.

Kuk, Y.I., J.S. Shin, N.R. Burgos, T.E. Hwang, O. Han, B.H. Cho, S. Jung, and J.O. Guh. 2003. Antioxidative enzymes offer protection from chilling damage in rice plants. Crop Sci. 43: 2109-2117, doi: 10.2135/cropsci2003.2109.

Laurent, A.S., I.A. Merwin, and J.E. Thies. 2008. Long-term orchard groundcover management systems affect soil microbial communities and apple replant disease severity. Plant Soil 304:209-225, doi: 10.1007/s11104-008-9541-4.

Li, M., W.H. Wang, R. Wang, and R.J. Liu. 2004. Influences of high temperature stress on activity of cell defense enzymes and membrane permeability in leaves of spinach. Acta Hort. Sin. 31:99-100, doi: 10.1300/J064v24n01_09.

Li, Y., H. Lu, Q. Cheng, R. Li, S. He, and B. Li. 2016. Changes of reactive oxygen species and scavenging enzymes of persimmon fruit treated with $\mathrm{CO}_{2}$ deastringency and the effect of hydroxyl radicals on breakdown of cell wall polysaccharides in vitro. Scientia Hort. 199:81-87, doi: 10.1016/j. scienta.2015.12.040.

Liu, J., M. Wisniewski, T. Artlip, Y. Sui, S. Droby, J. Norelli. 2013. The potential role of PR-8 gene of apple fruit in the mode of action of the yeast antagonist, Candida oleophila, in postharvest biocontrol of Botrytis cinerea. Postharvest Biol. Tec. 85:03-209, doi: 10.1016/j. postharvbio.2013.06.007.

Lv, X., Y. Yang, X. Lu, J. Jin, and R. Bai. 2017. Effects of $\mathrm{CaCl}_{2}$ on the AsA-GSH cycle of sour jujube seedlings under $\mathrm{NaCl}$ stress. Acta Hortic Sin. 44:953-962, doi: 10.16420/j.issn. 0513-353x.2016-0786.

Mandal, S., M. Mallick, and A. Mitra. 2009. Salicylic acid-induced resistance to Fusarium oxysporum $f$. $\mathrm{sp}$. lycopersici in tomato. Plant Physiol. Biochem. 47:642-649, doi: 10.1016/j. plaphy.2009.03.001.

Manici, L.M., M. Kelderer, I.H. Franke-Whittle, T. Ruhmer, G. Baab, and F. Nicoletti. 2013. Relationship between root-endophytic microbial communities and replant disease in specialized apple growing areas in Europe. Appl. Soil Ecol. 72:207-214, doi: 10.1016/j.apsoil.2013. 07.011 .

Manici, L.M., M. Kelderer, G. Erschbaumer, F. Caputo, V. Babini, and C. Casera. 2003. Replant problems in South Tyrol: Role of fungal pathogens and microbial populations in conventional and organic apple orchards. Plant Soil 256: 315-324, doi: 10.1023/A:1026103001592.

Mauch, F., B. Mauch-Mani, and T. Boller. 1988. Antifungal hydrolases in pea tissue: II. Inhibition of fungal growth by combinations of chitinase and $\beta$-1,3-glucanase. Plant Physiol. 88:936-942, doi: $10.2307 / 4271680$.

Mazzola, M. and L.M. Manici. 2012. Apple replant disease: Role of microbial ecology in cause and control. Annu. Rev. Phytopathol. 50:45-65, doi: 10.1146/annurev-phyto-081211-173005.
Mditshwa, A., O.A. Fawole, F. Vries, V.D.M. Kobus, E. Crouch, and U.L. Opara. 2017. Impact of dynamic controlled atmospheres on reactive oxygen species, antioxidant capacity and phytochemical properties of apple peel (cv. Granny Smith). Scientia Hort. 216:169-176, doi: 10.1016/j.scienta.2017.01.011.

Meng, L.L., C.L. Yu, D.S. Xue, B.H. Li, W.X Liang, and C.X. Wang. 2019. Control efficiency of BHT against postharvest apple grey mold and its influence on the activity of defensive enzymes and content of malondialdehyde. J. Plant Protection 46:686-692, doi: 10.13802/ j.cnki.zwbhxb.2019.2018048.

Mohsin, T. and N.S. Adnan. 2017. An insight into salt stress tolerance mechanisms of Chenopodium album. Environ. Sci. Pollut. Res. Intl. 24:1653116535, doi: 10.1007/s11356-017-9337-2.

Odintsova, T.I., A.A. Vassilevski, A.A. Slavokhotova, A.K. Musolyamov, E.I. Finkina, N.V. Khadeeva, V.A. Pukhalsky, E.V. Grishin, and T.A. Egorov. 2010. A novel antifungal hevein-type peptide from Triticum kiharae seeds with a unique 10-cysteine motif. FEBS J. 276:42664275, doi: 10.1111/j.1742-4658.2009.07135.x.

Patterson, B.D., E.A. Macrae, and I.B. Ferguson. 1984. Estimation of hydrogen peroxide in plant extracts using titanium (IV). Anal. Biochem. 139: 487-492, doi: 10.1016/0003-2697(84)90039-3.

Radwan, D.E.M., K.A. Fayez, S.Y. Mahmoud, and G. Lu. 2010. Modifications of antioxidant activity and protein composition of bean leaf due to bean yellow mosaic virus infection and salicylic acid treatments. Acta Physiol. Plant. 32:891-904, doi: 10.1007/s11738-010-0477-y.

Sels, J., J. Mathys, B.M.A.D. Coninck, B.P.A. Cammue, and M.F.C.D. Bolle. 2008. Plant pathogenesis- related (PR) proteins: A focus on PR peptides. Plant Physiol. Biochem. 46:941-950, doi: 10.1016/j.plaphy.2008.06.011.

Sharma, P. and R.S. Dubey. 2007. Involvement of oxidative stress and role of antioxidative defense system in growing rice seedlings exposed to toxic concentrations of aluminum. Plant Cell Rep. 26:2027-2038, doi: 10.1007/s00299-007-0416-6.

Shetty, N.P., H.J.L. Jrgensen, J.D. Jensen, D.B. Collinge, and H.S. Shetty. 2008. Roles of reactive oxygen species in interactions between plants and pathogens. Eur. J. Plant Pathol. 121:267-280, doi: 10.1007/s10658-008-9302-5.

Spath, M., H. Insam, U. Peintner, M. Kelderer, R. Kuhnert, and I.H. Frank-Whittle. 2015. Linking soil biotic and abiotic factors to apple replant disease: A greenhouse approach. J. Phytopathol. 163:287-299, doi: 10.1111/jph.12318.

Sun, T.H., J. Li, T. Wang, N. Ning, and J.Z. Xu. 2018. Difference in protein expression of apple leaves with different resistance response to Botryosphaeria berengeriana f. sp. piricola Infection. Acta Hort. Sin. 45:409-420, doi: 10.16420/j.issn.0513-353x.

Tewoldemedhin, Y.T., M. Mazzola, W.J. Botha, C.F.J. Spies, and A. Mcleod. 2011 a. Characterization of fungi (Fusarium and Rhizoctonia) and oomycetes (Phytophthora and Pythium) associated with apple orchards in South Africa. Eur. J. Plant Pathol. 130:215-229, doi: 10.1007/ s10658-011-9747-9.

Tewoldemedhin, Y.T., M. Mazzola, I. Labuschagne, and A. Mcleod. 2011b. A multi-phasic approach reveals that apple replant disease is caused by multiple biological agents with some agents acting synergistically. Soil Biol. Biochem. 43:1917-1927, doi: 10.1016/j.soilbio. 2011.05.014.

Tewoldemedhin, Y.T., M. Mazzola, L. Mostert, and A. Mcleod. 2011c. Cylindrocarpon species associated with apple tree roots in South Africa and their quantification using real-time PCR. Eur. J. Plant Pathol. 129:637-651, doi: 10.1007/s10658-010-9728-4.

Tian, S., R. Torres, A.R. Ballester, B. Li, L. Vilanova, and L. Gonzalez-Candelas. 2015. Molecular aspects in pathogen-fruit interactions: Virulence and resistance. Postharvest Biol. Technol. 122:11-21, doi: 10.1016/j.postharv bio.2016.04.018

Tilston, E.L., G. Deakin, J. Bennett, T. Passey, N.B. Harrison, F. O'Brien, F. Fernandez, and X.M. Xu. 2018. Candidate causal organisms for apple replant disease in the UK. Phytobiomes J. 2: 261-274, doi: 10.1094/PBIOMES-11-18-0050-R.

Van Loon, L.C., M. Rep, and C.M.J. Pieterse. 2006. Significance of inducible defense-related proteins in infected plants. Annu. Rev. Phytopathol. 44: 135-162, doi: 10.1146/annurev.phyto.44.070505. 143425.

Van Schoor, L., S. Denman, and N. Cook. 2009. Characterisation of apple replant disease under South African conditions and potential biological management strategies. Scientia Hort. 119:153162, doi: 10.1016/j.scienta.2008.07.032.

Vigers, A.J., S. Wiedemann, W.K. Roberts, M. Legrand, C.P. Selitrennikoff, and B. Fritig. 1992. Thaumatin-like pathogenesis-related proteins are antifungal. Plant Sci. 83:155-161, doi: 10.1016/0168-9452(92)90074-V.

Wang, C.X., X.L. Chen, and B.H. Li. 2014a. Effects of Valsa mali var. mali infection on defense enzymes activity and MDA content in apple callus. Chih Wu Sheng Li Hsueh T'ung Hsun 50:909-916, doi: 10.13592/j.cnki.ppj. 2013.0468.

Wang, G.S. 2018. Studies on fungal community in replanted soil around Bohai Gulf and alleviation apple replant disease by mixed cropping with Album fistulosum L. Doctoral dissertation, Shandong Agriculture University, Tai'an.

Wang, G.S., C.M. Yin, F.B. Pan, X.B. Wang, L. Xiang, Y.F. Wang, J.Z. Wang, C.P. Tian, J. Chen, and Z.Q. Mao. 2018a. Analysis of the fungal community in apple replanted soil around Bohai Gulf. Hort. Plant J. 4:5-11, doi: 10.1016/j.hpj.2018.05.003.

Wang, H., L. Yang, Y. Li, J. Hou, J. Huang, and W. Liang. 2016. Involvement of ABA- and $\mathrm{H}_{2} \mathrm{O}_{2}$-dependent cytosolic glucose-6-phosphate dehydrogenase in maintaining redox homeostasis in soybean roots under drought stress. Plant Physiol. Biochem. 107:126-136, doi: 10.1016/ j.plaphy.2016.05.040.

Wang, M., Y. Sun, G. Sun, X. Liu, L. Zhai, and Q. Shen. 2015a. Water balance altered in cucumber plants infected with Fusarium oxysporum f. sp. cucumerinum. Sci. Rep. 5:7722, doi: $10.1038 /$ srep07722.

Wang, N., Y. Zheng, N.B. Duan, Z.Y. Zhang, X.H. Ji, S.H. Jiang, S. Sun, L. Yang, Y. Bai, Z.J. Fei, and X.S. Chen. 2015b. Comparative transcriptomes analysis of red- and whitefleshed apples in an $F_{1}$ population of Malus sieversii $f$. niedzwetzkyana crossed with $M$. domestica 'Fuji'. PLoS One 10:e0133468, doi: 10.1371/journal.pone. 0133468.

Wang, S., K. Zhang, X. Huang, Y. Fan, L. Yang, and R. Li. 2015c. Cloning and functional analysis of thylakoidal ascorbate peroxidase (TAPX) gene in sugarcane. Sugar Tech 17:356-366, doi: 10.1007/s12355-014-0354-x.

Wang, X., Y. Ma, C. Huang, Q. Wan, N. Li, and Y. Bi. 2008. Glucose-6-phosphate dehydrogenase plays a central role in modulating reduced glutathione levels in reed callus under salt stress. Planta 227:611-623, doi: 10.1007/ s00425-007-0643-7. 
Wang, X.D., W.S. Bi, J. Gao, X.M. Yu, H.Y. Wang, and D.Q. Liu. 2018b. Systemic acquired resistance, $N P R 1$, and pathogenesis-related genes in wheat and barley. J. Integr. Agr. 17:6034560347, doi: 10.1016/S2095-3119(17)61852-5.

Wang, Y.F., F.B. Pan, X. Zhan, G.S. Wang, G.D. Zhang, Y.L. Hu, X.S. Chen, and Z.Q. Mao. 2015d. Effects of five kinds of phenolic acid on the function of mitochondria and antioxidant systems in roots of Malus hupehensis Rehd. Seedlings. Acta Ecol. Sin. 35:6566-6573, doi: 10.5846/stxb201402180284.

Wang, Y.F., F.B. Pan, G.S. Wang, G.D. Zhang, Y.L. Wang, X.S. Chen, and Z.Q. Mao. 2014b. Effects of biochar on photosynthesis and antioxidative system of Malus hupehensis Rehd. seedlings under replant conditions. Scientia Hort. 175:9-15, doi: 10.1016/j.scienta.2014.05.029.

Wang, Y.F., Z.T. Ma, X.W. Wang, Q.R. Sun, H. Dong, G. Wang, X. Chen, C.M. Yin, Z.H. Han, and Z.Q. Mao. 2019. Effects of biochar on the growth of apple seedlings, soil enzyme activities and fungal communities in replant disease soil. Sci. Hort. 256:108641, doi: 10.1016/j.scienta.2019.108641.

Xing, J.H., D.Z. Pan, F.L. Tan, and W. Chen. 2017. Effects of $\mathrm{NaCl}$ stress on the osmotic substance contents in Kandelia candel roots. Ecol. Envir. Sci. 26:1865-1871, doi: 10.16258 j.cnki.1674-5906.2017.11.006.

Yan, K., G. Han, C. Ren, S. Zhao, X. Wu, and T. Bian. 2018. Fusarium solani infection depressed photosystem performance by inducing foliage wilting in apple seedlings. Front. Plant Sci. 9: doi: $10.3389 /$ fpls.2018.00479.

Yim, B., K. Smalla, and T. Winkelmann. 2013. Evaluation of apple replant problems based on different soil disinfection treatments-links to soil microbial community structure? Plant Soil 366:617-631, doi: 10.1007/s11104-0121454-6.

Yin, C.M., M. Wang, J.Y. Wang, X.S. Chen, X. Shen, M. Zhang, and Z.Q. Mao. 2017a. The research advance on apple replant disease. Acta Hort. Sin. 44:2215-2230, doi: 10.16420/j. issn.0513-353x.2017-0524.

Yin, C.M., Y.N. Duan, L. Xiang, G.S. Wang, X.F. Zhang, X. Shen, X.S. Chen, M. Zhang, and Z.Q. Mao. 2018. Effects of phloridzin, phloretin and benzoic acid at the concentrations measured in soil on the root proteome of Malus hupehensis Rehd Seedlings. Scientia Hort. 228:10-17, doi: 10.1016/j.scienta.2017.09.044.
Yin, L., Y. Zou, M. Li, X. Ke, C. Li, D. Liang, and F.W. Ma. 2013. Resistance of Malus plants to Diplocarpon mali infection is associated with the antioxidant system and defense signaling pathways. Physiol. Mol. Plant Pathol. 84:146-152, doi: 10.1016/j.pmpp.2013.10.001.

Zhang, C.X., Y. Tian, L.Y. Zhang, L. Xiao, G.D. Kang, and P.H. Cong. 2015. Proteomic analysis of pathogen-responsive proteins from the bark of apple branches induced by Botryosphaeria dothidea. Acta Phytopathologica Sin. 45:280-287, doi: 10.13926/j.cnki. apps.2015.03.007.

Zhang, H.X. and Z.S. Shi. 2015. Research progress of maize salt tolerance. Seed 34:47-50, doi: 10.16590/j.cnki.1001-4705.2015.10.047.

Zhang, L., J. Liu, and X.M. Wang. 2013. Glucose-6phosphate dehydrogenase acts as a regulator of cell redox balance in rice suspension cells under salt stress. Plant Growth Regulat. 69:139-148, doi: 10.1007/s10725-012-9757-4.

Zhang, Y., X. Shi, B. Li, Q. Zhang, W. Liang, and C. Wang. 2016. Salicylic acid confers enhanced resistance to Glomerella leaf spot in apple. Plant Physiol. Biochem. 106:64-72, doi: 10.1016/j. plaphy.2016.04.047. 